03

\title{
О газоструйном методе осаждения наноструктурных пленок серебра
}

\author{
( Н.Ю. Быков, ${ }^{1}$ А.И. Сафонов, ${ }^{2}$ Д.В. Лещев, ${ }^{1}$ С.В. Старинский,, 2 А.В. Булгаков ${ }^{2}$ \\ ${ }^{1}$ Санкт-Петербургский политехнический университет Петра Великого, \\ 195251 Санкт-Петербург, Россия \\ ${ }^{2}$ Институт теплофизики им. С.С. Кутателадзе СО РАН, \\ 630090 Новосибирск, Россия \\ e-mail: bykov_nyu@spbstu.ru
}

Поступило в Редакцию 10 апреля 2018 г.

В окончательной редакции 10 апреля 2018 г.

Принято к публикации 15 декабря 2018 г.

\begin{abstract}
Проведены экспериментальное и теоретическое исследования синтеза тонких пленок серебра методом газоструйного осаждения. При осаждении металла из сверхзвуковой струи паров серебра с несущим газом гелием на кремниевые подложки получены наноструктурные пленки с размером наноструктур 3-30 nm для диапазона температур источника струи 1230-1380 К. Методом прямого статистического моделирования получены данные о газодинамике струи Ag-Не при разлете в вакуум (скорость, температура, концентрация, поток частиц на подложку) в зависимости от параметров в источнике (температура пара, расход несущего газа). Определен диапазон оптимальных расходов гелия, когда эффективность газоструйного источника максимальна. Установлено, что наличие фонового газа в камере осаждения при давлении более 1 Ра приводит к уменьшению потока частиц на подложку, и предложен простой способ его оценки. С помощью моделирования определены условия формирования в струе кластеров серебра. Показано, что для экспериментальных режимов осаждения кластеры в струе отсутствуют, а наблюдаемые наноструктуры серебра формируются на поверхности подложки.
\end{abstract}

DOI: 10.21883/JTF.2019.06.47628.146-18

\section{Введение}

Тонкие пленки благородных металлов обладают целым рядом уникальных свойств, благодаря чему представляют большой научный интерес и находят широкое применение в различных приложениях [1-4]. Вместе с тем продолжают развиваться методы их получения, такие как термовакуумное напыление [5], импульсная лазерная абляция [5-7], магнетронное и ионное распыления [8-10], газоструйное осаждение [11-14] и другие. Все эти методы основаны на диспергировании исходного массивного материала на элементарные составляющие (атомы, димеры, кластеры, наночастицы и даже микрокапли) с их выносом в разреженную атмосферу и последующей сборкой в тонкие наноструктурные пленки в результате целого ряда процессов на поверхности подложки [7,15-17]. Не менее важными являются процессы, происходящие с диспергированными элементами при движении к подложке, в частности, ускорение и конденсация (кластеризация) частиц в потоке, определяющие размер, состав и кинетическую энергию осаждаемых частиц. В этой связи особый интерес представляет метод вакуумного газоструйного осаждения (ВГСО). Суть метода состоит в создании сверхзвуковой струи смеси пара металла и инертного газа при ее истечении через сопло в вакуумную камеру и осаждении частиц струи на поверхность подложки с формированием металлической пленки. Наличие инертного газа позволяет регулировать интенсивность потока паров металла к подложке, а также создавать условия для кластеризации и управля- емого роста кластеров в струе. Присутствие кластеров в осаждаемом потоке может существенно повлиять на процессы, протекающие на подложке, определяя тем самым структуру получаемой пленки и соответственно другие ее свойства (оптические, каталитические, сенсорные) $[5-7,13,18]$.

Несмотря на большую историю метода ВГСО и относительную простоту его реализации, механизмы формирования наноструктурных пленок этим методом изучены недостаточно, что затрудняет эффективный контроль процесса синтеза пленок. В значительной степени это обусловлено сложностью экспериментального исследования струи паров металлов. Оптимизация процесса ВГСО осуществляется, как правило, эмпирическим путем на основе сопоставления свойств получаемых пленок с условиями осаждения. Это дает лишь косвенную информацию о потоке, составе и скоростях осаждаемых частиц.

Существенно расширить представление о протекающих процессах, а также получить информацию о газодинамических параметрах осаждаемого потока, позволяет применение расчетных методов исследования. Поскольку течения, возникающие при осаждении тонких пленок, в большинстве случаев являются разреженными, для их расчета может быть эффективно применен метод прямого статистического моделирования (ПСМ), являющийся традиционным методом численного исследования разреженных и околоконтинуальных течений [19]. Дополненный моделями физико-химических реакций в объеме метод позволяет моделировать течения с процессами 
конденсации в струях газов и паров [20-22], а также при лазерной абляции различных материалов [23-25].

Настоящая работа посвящена экспериментальному исследованию и численному моделированию методом ПСМ процессов вакуумного газоструйного осаждения наноструктурных пленок серебра с использованием несущего газа гелия. Целями настоящей работы являются: 1) анализ газодинамической картины течения, в том числе изучение влияния несущего газа на особенности расширения паров серебра; 2) исследование условий, при которых наблюдаются процессы формирования кластеров непосредственно в струе; 3) анализ механизмов формирования тонкой наноструктурной пленки при газоструйном осаждении серебра.

\section{1. Осаждение тонких пленок методом ВГСО}

Схема источника ВГСО, используемого в настоящей работе для осаждения пленок серебра, приведена на рис. 1, a. Резистивный нагреватель источника 1 выполнен из молибденовой проволоки, намотанной на трубу из кварцевого стекла, расположенной на основании 2 из нержавеющей стали. Внутри трубы располагается молибденовый тигель 3, схема которого приведена на рис. $1, b$. Инертный несущий газ (гелий) подается в тигель с объемным расходом $Q_{\mathrm{He}}$ через трубку 4. В тигле газ прогревается в кольцевом канале 5 и подается на поверхность расплавленного серебра 6 . Температура тигля/расплава $T_{0}$ контролировалась хромельалюмелевыми термопарами. Испаренные с поверхности расплава атомы Ag смешиваются в тигле с атомами гелия, и образовавшаяся смесь истекает через сопловой блок 7 с радиусом выходного отверстия $R=1.5 \mathrm{~mm}$ в вакуумную камеру (остаточное давление $1 \mathrm{~Pa}$ ). Образовавшаяся струя направлена на подложку 8 , находящуюся при температуре $T_{s}$ и расположенную на расстоянии $L$ от среза сопла источника, на поверхности которой осаждаются пленки металла. Для снижения тепловых потерь источника используются тепловые экраны 9-11. Экраны 10 дополнительно защищают подложку от нагрева тепловым излучением.

С помощью данного источника были осаждены тонкие пленки серебра на подложки монокристаллического кремния (100). Осаждение проведено при температуpe тигля в диапазоне $T_{0}=1230-1380 \mathrm{~K}$ при фиксированном объемном расходе гелия $Q_{\mathrm{He}}=36 \mathrm{sccm}$. Расстояние сопло-подложка варьировалось в диапазоне $L=70-100 \mathrm{~mm}$. Методом сканирующей электронной микроскопии (СЭМ, микроскоп JEOL JSM-6700F) был проведен анализ морфологии покрытий, полученных при различных режимах осаждения, оценен объем полученных наноструктур на поверхности, восстановлена средняя толщина покрытий. На основании этих данных был оценен массовый расход паров серебра на оси струи.

\section{2. Моделирование течения смеси пара серебра с гелием}

Расчеты течения, возникающего при газоструйном осаждении, выполнены методом прямого статистического моделирования в осесимметричной постановке (рис. $1, c)$. Потоки атомов гелия и серебра через поверхности, перпендикулярные оси течения, моделируются согласно выражению [19]:

$$
F^{+}=n\left(k T_{0} /(2 \pi m)\right)^{1 / 2}\left\{\exp \left(-s^{2}\right)+\pi^{1 / 2} s(1+\operatorname{erf}(s))\right\},
$$

где $n-$ концентрация частиц, $m$ - масса частицы, $s=V /\left(2 k T_{0} / m\right)^{1 / 2}$ - скоростное отношение $(V-$ среднемассовая скорость частиц), erf - интеграл вероятности, $k$ - постоянная Больцмана.

Функция распределения по скоростям для частиц, вбрасываемых в расчетную область, задается как максвелловская с направленной скоростью

$$
\begin{aligned}
f^{+}= & n m^{3 / 2} /\left(2 \pi k T_{0}\right)^{3 / 2} \\
& \times \exp \left(-m\left\{\left(v_{x}-V\right)^{2}+v_{y}^{2}+v_{z}^{2}\right\} /\left(2 k T_{0}\right)\right),
\end{aligned}
$$

где $v_{x}>0$ для $\mathrm{Ag}$ и $v_{x}<0$ для Не. Для испаряющихся с поверхности 1 атомов серебра поток внутрь области $F_{s, \text { Ag }}^{+}$соответствует закону Герца-Кнудсена - выражению (1) с параметрами $s_{\mathrm{Ag}}=0\left(V_{\mathrm{Ag}}=0\right), n=n_{0, \mathrm{Ag}}\left(T_{0}\right)$, $m=m_{\mathrm{Ag}}$, где $n_{0, \mathrm{Ag}}\left(T_{0}\right)=p_{0, \mathrm{Ag}}\left(T_{0}\right) /\left(k T_{0}\right)-$ концентрация насыщенного пара атомов серебра, $s_{\mathrm{Ag}}, V_{\mathrm{Ag}}, m_{\mathrm{Ag}}-$ скоростное отношение, среднемассовая скорость и масса атомов серебра соответственно. Давление насыщенного пара $p_{0, \mathrm{Ag}}\left(T_{0}\right)$ определяется согласно данным [26]. Атомы серебра, возвращающиеся обратно на поверхность 1 , конденсируются на ней и исключаются из расчета. От остальных внутренних поверхностей источника, включая сопловой блок, атомы отражаются диффузно с полной аккомодацией энергии с температурой $T_{0}$. Все атомы серебра, падающие на поверхности тепловых экранов 10, конденсируются на них (исключаются из расчета). Вылетающие из расчетной области через поверхности 9,11-14 (рис. 1,c) атомы также исключаются из расчета.

Полный поток атомов гелия $F_{\mathrm{He}}$ через поверхность 2 задается в соответствии с экспериментальным значением объемного расхода гелия $Q_{\mathrm{He}}$. Параметры $n_{\mathrm{He}}, V_{\mathrm{He}}$ в уравнении (1) неизвестны, и в расчетах принимается $s_{\mathrm{He}}=0.1$, а $n_{\mathrm{He}}$ определяется из (1). Атомы гелия, возвращающиеся обратно на поверхность 2, зеркально отражаются от нее. От прочих поверхностей источника и тепловых экранов 10 атомы гелия отражаются диффузно с полной аккомодацией энергии с температурой $T_{0}$. Пересекающие поверхности 9,11-14 атомы исключаются из расчета.

Упругие столкновения атомов гелия рассчитываются с использованием модели сфер переменной твердости (VHS-модель), с параметрами [19]: $d_{r e f, \mathrm{He}}=2.33 \AA$, 


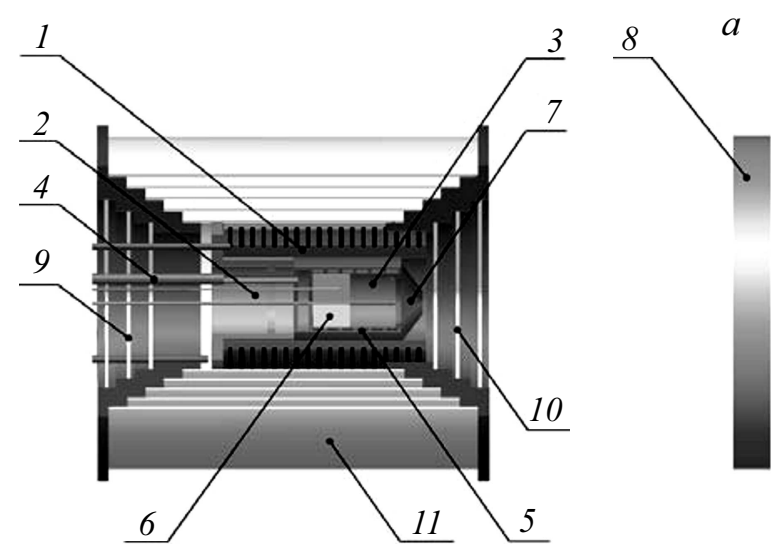

$b$

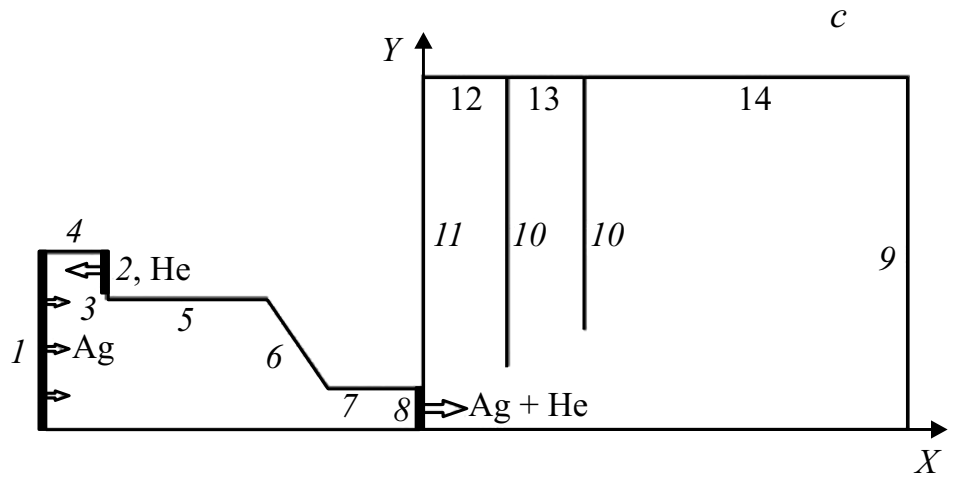

Рис. 1. $a$ - схема установки ВГСО: 1 - нагреватель, 2 - держатель тигля, 3 - тигель, 4,5 - трубка и кольцевой канал подачи несущего газа, 6 - серебро, 7 - сопловой блок, 8 - подложка, 9-11- тепловые экраны; $b-$ схема высокотемпературного источника (тигля); $c$ - схема расчетной области: 1 - поверхность расплава серебра, 2 - срез кольцевого канала подачи гелия, $3-5$ - внутренние поверхности тигля, 6,7- внутренние поверхности конфузорной и цилиндрической частей соплового блока, 8 - срез соплового блока, 9 - плоскость расположения подложки, 10 - экраны, $11-14$ - границы зоны расширения.

$T_{\text {ref }, \mathrm{He}}=273 \mathrm{~K}, \omega_{\mathrm{He}}=0.66\left(d_{\text {ref }, \mathrm{He}}, T_{\text {ref }, \mathrm{He}}-\right.$ peперные значения диаметра столкновения и температуры, $\omega_{\mathrm{He}}$ - параметр, определяемый зависимостью вязкости газа от температуры). Диаметр атомов серебра при взаимных упругих столкновениях и столкновениях с атомами гелия полагался постоянным и равным вандер-ваальсовому диаметру $3.44 \AA$ [27]. Варианты расчетов, выполненные без учета процессов образования кластеров в струе, приведены в табл. 1. Для выявления роли несущего газа расход гелия в расчетах варьировался относительно экспериментального значения в диапазоне $Q_{\mathrm{He}}=3.6-1080 \mathrm{sccm}$. Ряд расчетов выполнен для случая струи чистого пара металла без несущего газа $\left(Q_{\mathrm{He}}=0\right.$, варианты $\left.1-4\right)$. В большинстве расчетов (кроме варианта 9) наличие подложки не учитывалось (предполагалось свободное пересечение атомами границы 9, рис. $1, c)$.

Часть расчетов (табл. 2) выполнена с учетом процессов формирования и роста/распада кластеров серебра в области расширения струи. Вследствие большой вычислительной трудоемкости ПСМ-моделирования течений с процессами конденсации расчет выполнен для упрощенной геометрии течения. Атомы гелия и серебра вбрасывались через границу 8 (срез соплового блока).
Условия на границе (потоки атомов гелия и серебра) соответствовали предварительному расчету без учета конденсации в полной геометрии, область расширения была ограничена расстоянием $15 R$ по продольной координате от выходного отверстия и $7 R$ по поперечной координате, наличие тепловых экранов не учитывалось.

В расчетах для кластеров $\mathrm{Ag}_{g}$ размера $g>2$ рассматривались реакции присоединения мономера к кластеру при парном столкновении

$$
\mathrm{Ag}+\mathrm{Ag}_{g-1} \rightarrow \mathrm{Ag}_{g}
$$

и мономолекулярный распад кластера:

$$
\mathrm{Ag}_{g} \rightarrow \mathrm{Ag}+\mathrm{Ag}_{g-1} .
$$

Прямой процесс (3) характеризуется константой скорости $K_{g-1}$, обратный процесс (4) константой скорости $K_{g}^{-}$.

Критической стадией формирования и роста кластеров при гомогенной конденсации является образование димера [28]. В рамках используемой модели димеры серебра образуются в результате трехчастичных столкновений:

$$
\begin{aligned}
& \mathrm{Ag}+\mathrm{Ag}+\mathrm{Ag} \rightarrow \mathrm{Ag}_{2}+\mathrm{Ag} \\
& \mathrm{Ag}+\mathrm{Ag}+\mathrm{He} \rightarrow \mathrm{Ag}_{2}+\mathrm{He} .
\end{aligned}
$$


Таблица 1. Варианты расчета течения с температурой источника до $1377 \mathrm{~K}$

\begin{tabular}{c|c|c|c|c|c|c|c|c}
\hline Вариант & $T_{0}, \mathrm{~K}$ & $n_{0, \mathrm{Ag}}, \mathrm{m}^{-3}$ & $Q_{\mathrm{He}}, \mathrm{sccm}$ & $T_{s t}, \mathrm{~K}$ & $K n_{\mathrm{Ag}}$ & $K n_{\mathrm{He}}$ & $F_{\mathrm{Ag}, e, \mathrm{~m}^{-2} \mathrm{~s}^{-1}}$ & $\begin{array}{c}F_{\mathrm{Ag}}(x=100 \mathrm{~mm}, \\
y=0), \mathrm{m}^{-2} \mathrm{~s}^{-1}\end{array}$ \\
\hline 1 & 1235 & $1.76 \cdot 10^{19}$ & 0 & - & 72.3 & - & $1.06 \cdot 10^{21}$ & $5 \cdot 10^{17}$ \\
2 & 1276 & $4.3 \cdot 10^{19}$ & 0 & - & 29.6 & - & $2.63 \cdot 10^{21}$ & $10^{18}$ \\
3 & 1314 & $8.3 \cdot 10^{19}$ & 0 & - & 15.3 & - & $5.17 \cdot 10^{21}$ & $2.2 \cdot 10^{18}$ \\
4 & 1377 & $2.63 \cdot 10^{20}$ & 0 & - & 4.8 & - & $1.7 \cdot 10^{22}$ & $7 \cdot 10^{18}$ \\
5 & 1128 & $2.5 \cdot 10^{18}$ & 36 & - & 508 & $\approx 0.6$ & $5.17 \cdot 10^{20}$ & $3.4 \cdot 10^{17}$ \\
6 & 1235 & $1.76 \cdot 10^{19}$ & 36 & - & 72.3 & $\approx 0.6$ & $3.68 \cdot 10^{21}$ & $2.3 \cdot 10^{18}$ \\
7 & 1276 & $4.3 \cdot 10^{19}$ & 36 & - & 29.6 & $\approx 0.6$ & $9.04 \cdot 10^{21}$ & $6 \cdot 10^{18}$ \\
8 & 1314 & $8.3 \cdot 10^{19}$ & 36 & - & 15.3 & $\approx 0.6$ & $1.75 \cdot 10^{22}$ & $1.2 \cdot 10^{19}$ \\
9 & 1377 & $2.63 \cdot 10^{20}$ & 36 & 585 & 4.8 & $\approx 0.6$ & $5.54 \cdot 10^{22}$ & $3.3 \cdot 10^{19}$ \\
10 & 1377 & $2.63 \cdot 10^{20}$ & 3.6 & - & 4.8 & $\approx 6$ & $2.03 \cdot 10^{22}$ & $9 \cdot 10^{18}$ \\
11 & 1377 & $2.63 \cdot 10^{20}$ & 36 & - & 4.8 & $\approx 0.6$ & $5.59 \cdot 10^{22}$ & $3.3 \cdot 10^{19}$ \\
12 & 1377 & $2.63 \cdot 10^{20}$ & 180 & - & 4.8 & $\approx 0.16$ & $9.9 \cdot 10^{22}$ & - \\
13 & 1377 & $2.63 \cdot 10^{20}$ & 360 & - & 4.8 & $\approx 0.09$ & $9.7 \cdot 10^{22}$ & $1.7 \cdot 10^{20}$ \\
& 1377 & $2.63 \cdot 10^{20}$ & 1080 & - & 4.8 & $\approx 0.03$ & $7.9 \cdot 10^{22}$ & $1.7 \cdot 10^{20}$
\end{tabular}

Таблица 2. Варианты расчета течения с учетом образования кластеров

\begin{tabular}{c|c|c|c|c|c|c|c|c}
\hline Вариант & $T_{0}, \mathrm{~K}$ & $Q_{\text {не }}, \mathrm{sccm}$ & $F_{\mathrm{Ag}, n z}, \mathrm{~m}^{-2} \mathrm{~s}^{-1}$ & Модель & Параметр $\Gamma^{*}$ & $K n_{e, \mathrm{Ag}}$ & $K n_{e, \text { Не }}$ & $\alpha_{c l}, \%$ \\
\hline 15 & 1377 & 0 & $1.7 \cdot 10^{22}$ & $\mathrm{SL}$ & 0.28 & 25 & - & 0 \\
16 & 1377 & 36 & $5.59 \cdot 10^{22}$ & $\mathrm{SL}$ & - & 10 & 2 & 0 \\
17 & 1773 & 0 & $4.1 \cdot 10^{24}$ & $\mathrm{SL}$ & 25.2 & 0.13 & - & $10^{-7}$ \\
18 & 1773 & 1000 & $7.8 \cdot 10^{24}$ & $\mathrm{SL}$ & - & 0.17 & 0.09 & $2 \cdot 10^{-6}$ \\
19 & 2123 & 0 & $7.1 \cdot 10^{25}$ & $\mathrm{SL}$ & 312 & 0.01 & - & $6 \cdot 10^{-4}$ \\
20 & 2123 & 5000 & $7.5 \cdot 10^{25}$ & $\mathrm{SL}$ & - & 0.025 & 0.019 & $8 \cdot 10^{-4}$ \\
21 & 2123 & 5000 & $7.5 \cdot 10^{25}$ & $\mathrm{LDV}$ & - & 0.025 & 0.019 & $0.5 \cdot 10^{-6}$
\end{tabular}

Обратные по отношению к (5) и (6) реакции протекают по схеме:

$$
\begin{aligned}
& \mathrm{Ag}_{2}+\mathrm{Ag} \rightarrow \mathrm{Ag}+\mathrm{Ag}+\mathrm{Ag}, \\
& \mathrm{Ag}_{2}+\mathrm{He} \rightarrow \mathrm{Ag}+\mathrm{Ag}+\mathrm{He} .
\end{aligned}
$$

Скорости прямых (5), (6) и обратных (7), (8) реакций обозначим как $K_{1(3), \mathrm{Ag}}, K_{1(3), \mathrm{He}}$ и $K_{2 c, \mathrm{Ag}}^{-}, K_{2 c}^{-}$, Не соответственно.

Для розыгрыша вероятности процесса (3) используется предположение о зависимости данного параметра только от размера кластера $g$ в соответствии с [29]. Вероятность реакции (4) зависит от внутренней энергии распадающегося кластера и параметров константы скорости мономолекулярного распада [30], вероятности реакций (5)-(8) зависят от полной энергии столкновения и параметров констант скоростей соответствующих реакций [19]. В используемой модели конденсации [30] константа равновесия процесса димеризации полагается равной $K_{c}=K_{2 c, \mathrm{Ag}}^{-} / K_{1(3), \mathrm{Ag}}=$ $=K_{2 c, \mathrm{He}}^{-} / K_{1(3), \mathrm{He}}=A T^{B} \exp \left\{-E_{a} /(k T)\right\} \quad\left(E_{a}-\right.$ энергия активации, $a$ и $B$ - константы), константы скоростей прямых реакций полагаются равными $K_{1(3), \mathrm{Ag}}=\alpha_{\mathrm{Ag}} T^{\beta_{\mathrm{Ag}}}$ для (5) и $K_{1(3), \mathrm{He}}=\alpha_{\mathrm{He}} T^{\beta_{\mathrm{He}}}$ для (6). В настоящей работе рассматриваются два варианта задания параметров констант скоростей. Первый набор параметров (далее SL): $A=10.86 \cdot 10^{33} \mathrm{~m}^{-3} \mathrm{~K}, B=-1, E_{a}=1.67 \mathrm{eV}$ согласно $[31], \quad \alpha_{\mathrm{Ag}}=0.89 \cdot 10^{-45} \mathrm{~m}^{6} \mathrm{~K}^{-0.5} \mathrm{~s}^{-1}, \quad \alpha_{\mathrm{He}}=$ $=3 \cdot 10^{-45} \mathrm{~m}^{6} \mathrm{~K}^{-0.5} \mathrm{~s}^{-1}$ и $\beta_{\mathrm{Ag}}=\beta_{\mathrm{He}}=0.5$ согласно упрощенной модели тройных столкновений [30,32]. Второй набор параметров (далее LDV) получен в настоящей работе на основе вычисленных термодинамических данных: $A=1.84 \cdot 10^{33} \mathrm{~m}^{-3} \mathrm{~K}^{-0.36}, B=0.36, E_{a}=1.61 \mathrm{eV}$, $\alpha_{\mathrm{Ag}}=8.99 \cdot 10^{-46} \mathrm{~m}^{6} \mathrm{~K}^{0.36} \mathrm{~s}^{-1}, \alpha_{\mathrm{He}}=3.14 \cdot 10^{-46} \mathrm{~m}^{6} \mathrm{~K}^{0.36} \mathrm{~s}^{-1}$ и $\beta_{\mathrm{Ag}}=\beta_{\mathrm{He}}=-0.36$. Расчеты проводились методом функционала плотности $\mathrm{wb} 97 \mathrm{xd} / \mathrm{lanl} 2 \mathrm{dz}$ программой Gaussian 09 [33], методика определения параметров констант скоростей реакций аналогична [34], при этом эффективность столкновений с атомами гелия заимствована из [35]. Следует обратить внимание, что параметры SL и LDV существенно отличаются в оценке констант скорости прямой реакции димеризации и равновесия $K_{c}$.

Остальные параметры, необходимые для моделирования процесса кластеризации приняты следующими: параметр, характеризующий поверхностную плотность атомов в кластере $\omega_{\mathrm{Zh}}=0.81$, координационное число жидкого серебра $N_{\mathrm{Zh}}=8.5$ [36], радиус Вингера-Зейца для жидкого серебра $r_{w, \mathrm{Ag}}=(3 m /(4 \pi \rho))^{1 / 3}=1.68 \AA$, расстояние между атомами в димере серебра $d_{d}=$ $=2.53 \AA$ [37]. Энергия отрыва мономера серебра от 

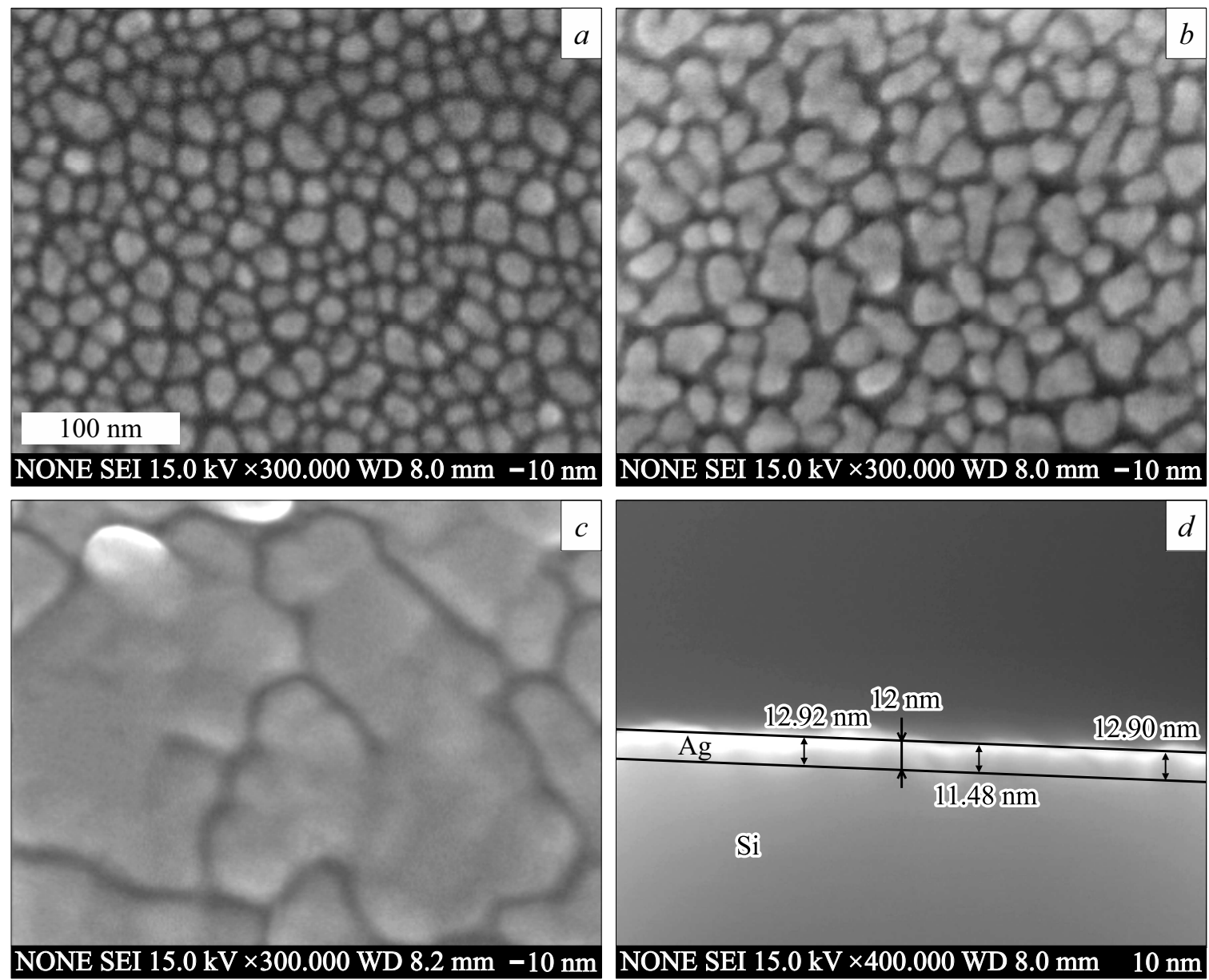

Рис. 2. СЭМ-снимки пленок серебра на кремниевых подложках для времени осаждения $600(a), 1200(b)$ и 2700 s $(c)$ (температура источника $1273 \mathrm{~K}$, расход гелия $36 \mathrm{sccm}$, расстояние „источник-подложка“ $70 \mathrm{~mm}), d$ - СЭМ-снимок торцевого слома пленки, изображенной на $b$.

плоской поверхности полагалась равной $\varepsilon_{\infty}=2.77 \mathrm{eV}$, энергия диссоциации димера серебра $\varepsilon_{2}=1.67 \mathrm{eV}$ [31]. Характерная частота колебаний мономеров в кластере принята $v_{0}=10^{-12} \mathrm{~s}^{-1}$ [38]. Энергообмен при неупругих столкновениях частиц описывался моделью Ларсена-Боргнакке [19], вероятность неупругого столкновения принималась равной 0.1 [20]. Число колебательных степеней свободы димера серебра $Z_{v, 2}=1$, кластеров больших размеров $Z_{v, g}=3 g-6$.

В расчетах использован параллельный алгоритм, основанный на принципе статической декомпозиции расчетной области.

\section{3. Результаты и обсуждение}

\section{1. Структура осаждаемой пленки}

На рис. 2 показана эволюция морфологии пленки в процессе осаждения серебра при увеличении времени осаждения. На начальной стадии формирования (время осаждения $600 \mathrm{~s}$ ) пленка обладает ярко выраженной островковой структурой, причем островки имеют либо сферическую, либо эллиптическую форму (рис. 2,a). Рост сферических островков происходит как в результате прямого поступления частиц из потока на их поверхность, так и за счет присоединения диффундирующих адатомов. По мере осаждения материала и роста островков происходит их коагуляция, о чем свидетельствует нарушение регулярности формы отдельных островков: на рис. $2, b$ каждый из островков представляет собой объединение сферических или эллиптических частиц, число которых примерно соответствует числу отдельных островков на рис. 2, а. Дальнейшее увеличение времени синтеза приводит сначала к формированию перколяционной структуры (рис. 2,c), а затем и к полному перекрытию поверхности подложки серебром.

На рис. 3 показаны СЭМ-фотографии пленок серебра, полученных при фиксированном времени осаждения, но для различных температур источника ВГСО в диапазоне $1233-1375 \mathrm{~K}$. Во всех случаях пленки являются наноструктурными, состоящими из индивидуальных наночастиц, средний размер которых увеличивается с ростом температуры источника от $\sim 6 \mathrm{~nm}$ при $1233 \mathrm{~K}$ до $\sim 17 \mathrm{~nm}$ при $1377 \mathrm{~K}$. При этом распределение частиц 

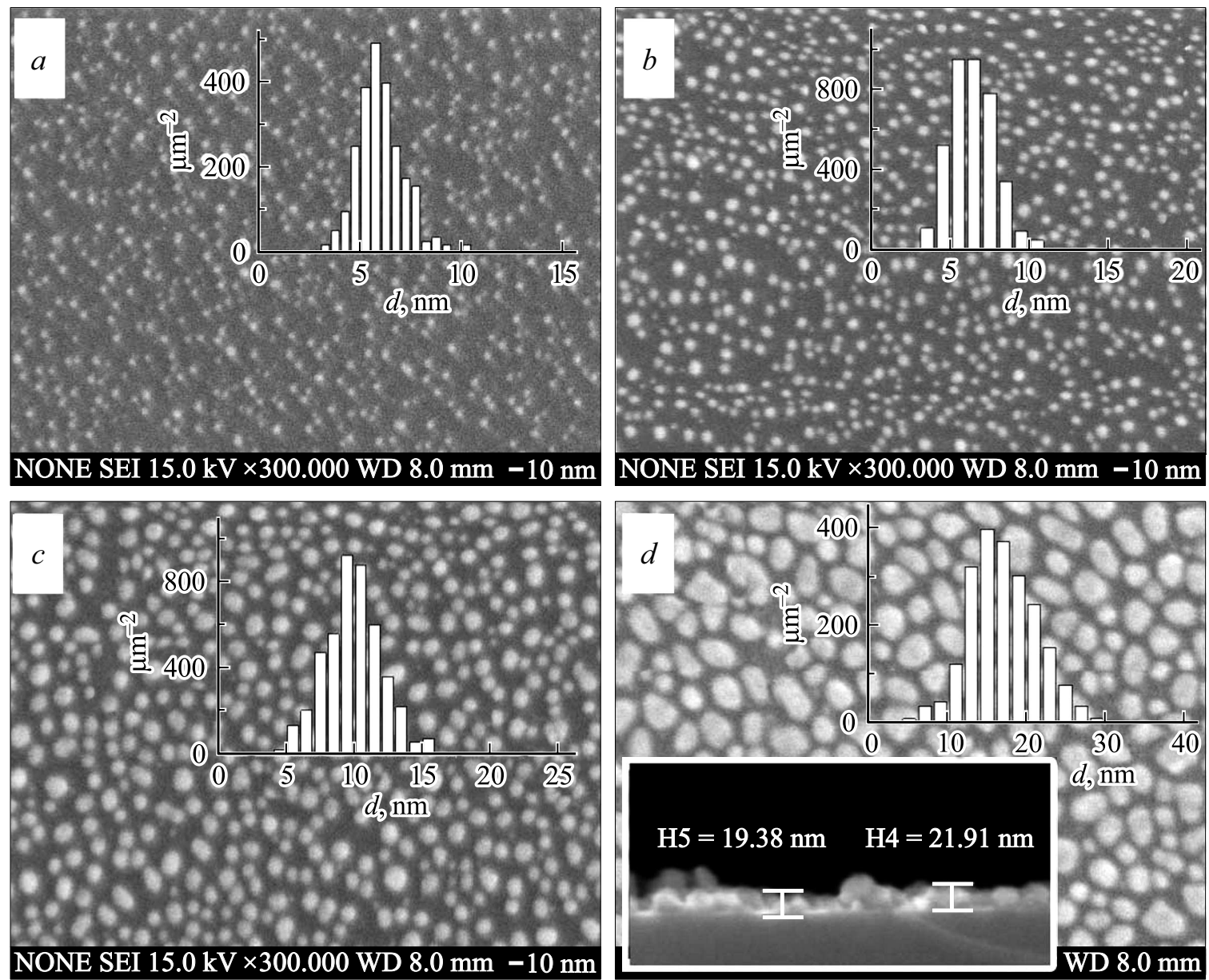

Рис. 3. СЭМ-снимки пленок, осажденных на подложку, разогретую до $473 \mathrm{~K}$, расстояние до источника $100 \mathrm{~mm}$, время осаждения $30 \mathrm{~min}$. Температура источника: $a-1233, b-1276, c-1314, d-1377 \mathrm{~K}$. На вставках представлены гистограммы распределения частиц по размерам, а также СЭМ-снимок торцевого слома образца.

по размерам является достаточно узким (см. приведенные на рис. 3 гистограммы). Снимок торцевого слоя пленки (рис. 3, $d$ ) свидетельствует о том, что наночастицы имеют форму, близкую к сферической.

Для формирования островковой структуры (рис. 2,a) при осаждении атомов металла необходимо наличие зародышей наночастиц на поверхности подложки [39]. Их формирование может происходить либо непосредственно на поверхности, либо в качестве зародышей могут выступать малые кластеры, образовавшиеся в струе $[7,40]$. Анализ конденсационных процессов в расширяющейся смеси „пар серебра-гелий“ невозможен без анализа газодинамики разлета струи, который был выполнен методом ПСМ.

\section{2. Течение смеси для малых температур источника}

В настоящем разделе представлены результаты расчеты течения смеси пара серебра с гелием для температур источника ниже $1377 \mathrm{~K}$ (табл. 1).
Определяющими параметрами в рассматриваемой постановке являются: температуры источника и тепловых экранов (а также подложки для варианта расчета 9), расход и давление несущего газа на входе в источник, геометрические размеры источника, размеры тепловых экранов и подложки. Для характеристики режима истечения смеси из источника удобно ввести числа Кнудсена $K_{n}=\lambda_{0} / R$ для гелия и пара серебра, рассчитанные по радиусу выходного отверстия $R$ и соответствующим длинам свободного пробега в источнике: $\lambda_{0, \mathrm{Ag}}-$ средняя длина свободного пробега атомов серебра, определенная по равновесной концентрацией пара $n_{0, \mathrm{Ag}}$ при температуре $T_{0}, \lambda_{0, \mathrm{He}}-$ средняя длина свободного пробега атомов инертного газа, рассчитанная по температуре $T_{0}$ и концентрации гелия в середине цилиндрической части источника $\left(n_{0, \mathrm{He}}\right)$.

В табл. 1 приведены данные о числах Кнудсена для гелия и пара серебра. При отсутствии расхода гелия (варианты 1-4) для паров серебра течение является близким к свободномолекулярному. При подаче гелия в источник с расходом 36-360 sccm смесь гелий-серебро истекает из источника в переходных по числу Кнудсена 

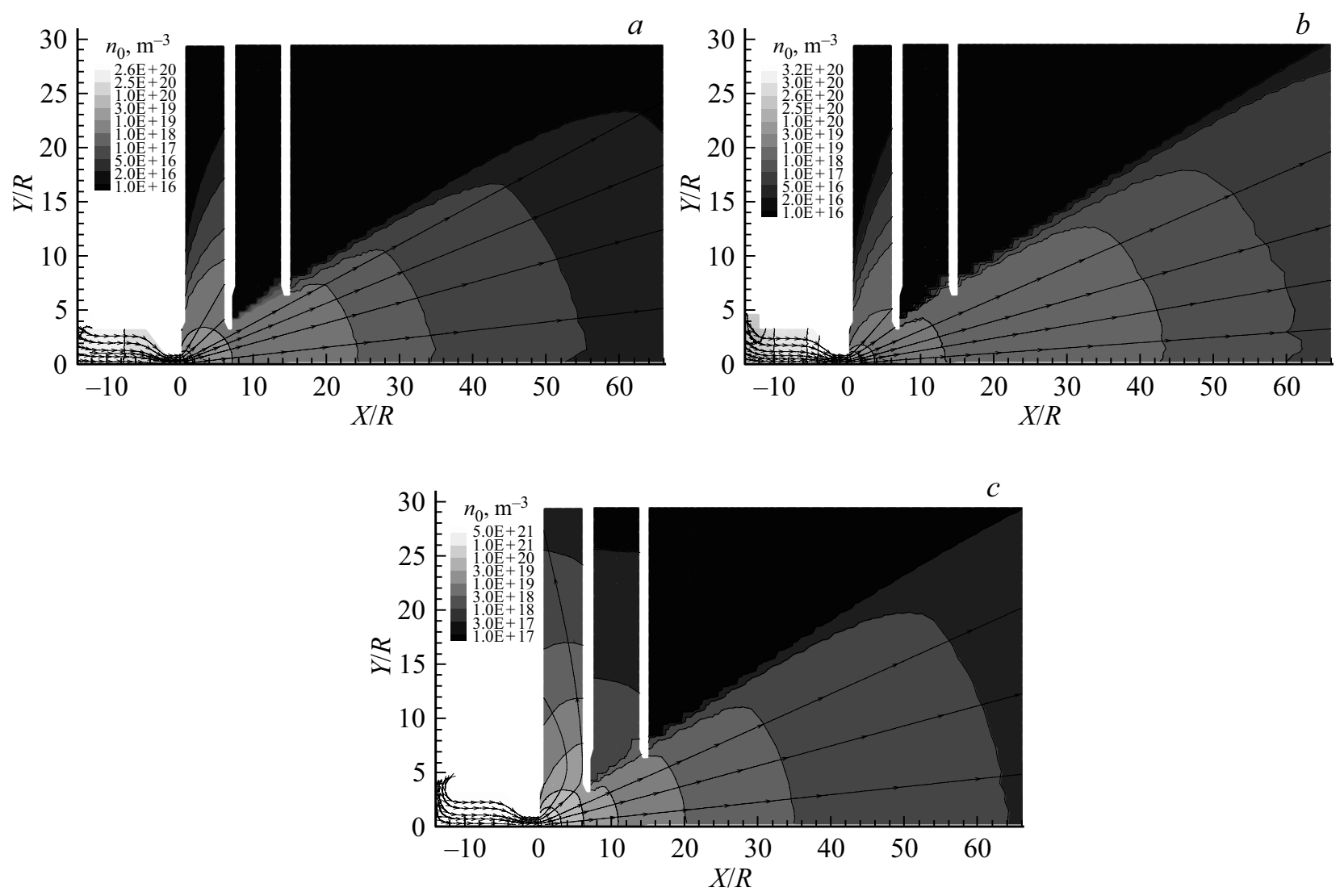

Рис. 4. Поля концентраций и линии тока в источнике и струе при температуре $T_{0}=1377 \mathrm{~K}: a-$ расчет пара серебра без гелия (вариант 4), $b, c$ - расчет смеси Ag-Не (вариант 11, $b$ - серебро, $c$ - гелий).

режимах, а при расходе гелия $1080 \mathrm{sccm}$ режим истечения близок к континуальному.

Расчеты показывают, что пары серебра составляют меньшую долю в смеси для рассматриваемого диапазона параметров (табл. 1, варианты 5-14). Мольная доля серебра увеличивается в процессе разлета, и ее значения в струе заметно превышают исходные значения в источнике. Для рассматриваемых условий расширения в вакуум концентрация серебра в струе замораживается на расстоянии примерно 15 радиусов от источника. Максимальная мольная доля паров серебра реализуется при максимальной температуре $T_{0}=1377 \mathrm{~K}$ и для расхода гелия $36 \mathrm{sccm}$ составляет около 4.5\% в источнике, достигая $\sim 12 \%$ в струе.

На рис. 4 представлены поля плотности атомов серебра и гелия для вариантов расчета 4 и $11\left(T_{0}=1377 \mathrm{~K}\right.$, $Q_{\text {не }}=0$ и $36 \mathrm{sccm}$ соответственно). Тепловые экраны 10 (рис. 1,c) для рассмотренных вариантов играют роль скиммера, отсекая от струи периферийную часть. Для варианта расчета 4 без гелия максимум плотности атомов серебра находится непосредственно у испаряемой поверхности (рис. 4,a). Далее по течению к соплу источника плотность уменьшается незначительно, оставаясь примерно постоянной, и резко падает в области выходного отверстия и в струе. В варианте 11 гелий поджимает пар серебра в источнике к входу в цилин- дрическую часть соплового блока. Максимум плотности пара серебра смещается от испаряемой поверхности к концу конфузорной части соплового блока. Плотность гелия имеет максимум в области кольцевой щели, остается примерно постоянной в цилиндрической части источника и снижается в выходном блоке источника и струе. Различие в условиях отражения атомов гелия и серебра от тепловых экранов, приводит к различию в полях параметров в областях, примыкающих к экранам (рис. 4, $b$ и $c$ ). Часть потока гелия, отражаясь от первого экрана, разворачивается и покидает расчетную область, через границу 11. Атомы серебра осаждаются на тепловых экранах, их поток через внешнюю границу области 11 практически равен нулю.

Типичные осевые распределения газодинамических параметров приведены на рис. 5 (для вариантов расчета 4 и 11). Течение паров серебра без несущего газа (вариант 4) является свободномолекулярным. Плотность пара монотонно падает, скорость растет примерно до значения средней тепловой скорости в источнике $u_{0, \mathrm{Ag}}=\left(8 k T_{0} /\left(\pi m_{\mathrm{Ag}}\right)\right)^{1 / 2}$, температура падает и „замораживается“ на некотором расстоянии от источника до значения, близкого к величине $(1-8 /(3 \pi)) T_{0}[41]$.

На рис. 5 приведены также теоретические зависимости для двух предельных случаев - аналитические данные [41] для бесстолкновительного течения из резер- 

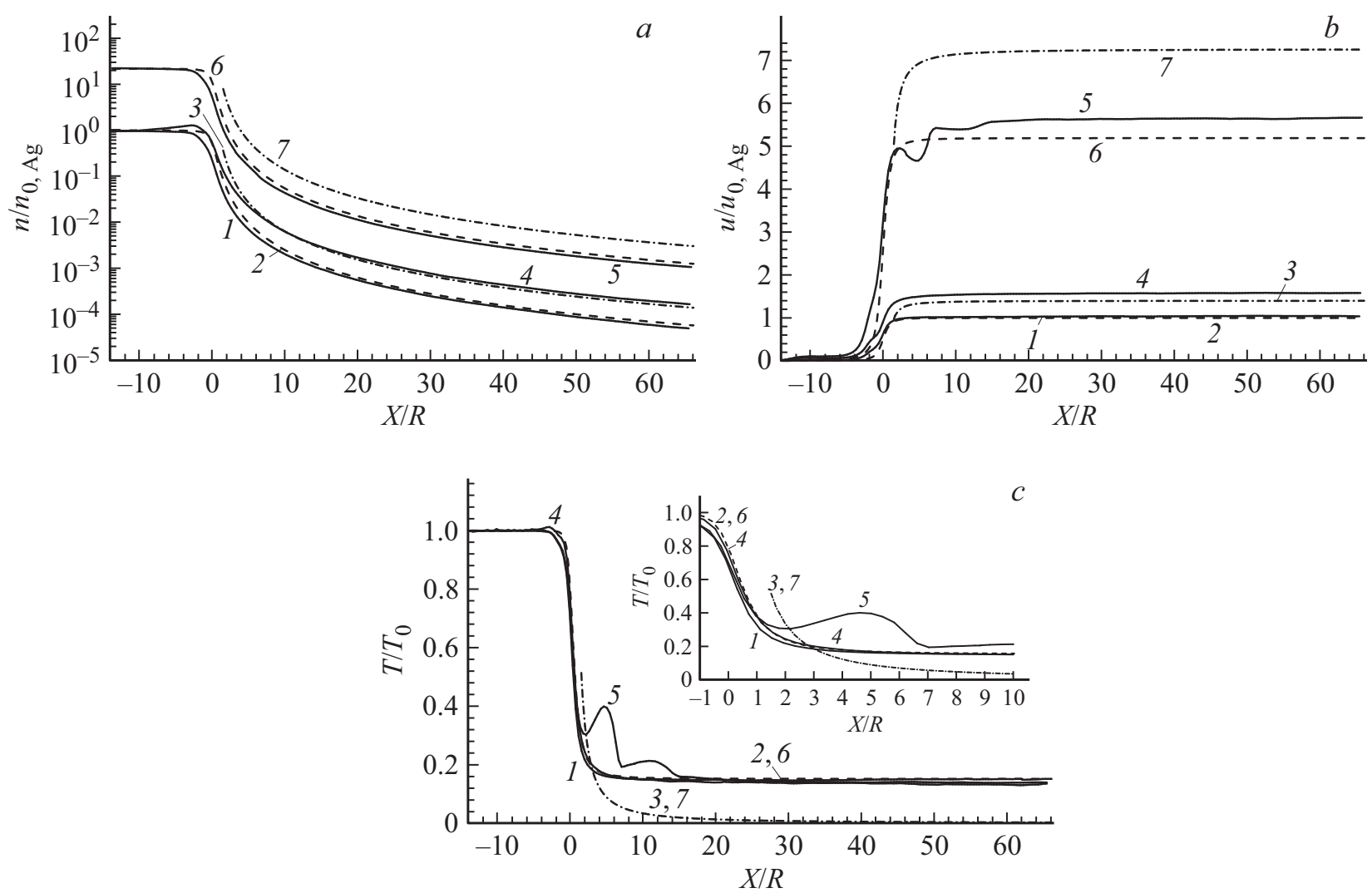

Рис. 5. Осевые распределения концентрации $(a)$, скорости $(b)$ и температуры $(c)$ при $T_{0}=1377 \mathrm{~K}$ для струи серебра без гелия (кривая 1, вариант расчета 4) и смеси $\mathrm{Ag}-\mathrm{He}(4-$ серебро, 5 - гелий, вариант 11). Кривые 2 и 6 - решение [41] для свободномолекулярного истечения пара серебра и гелия соответственно, кривые 3 и 7 - решение [42] для невязкой струи пара серебра и гелия соответственно.

вуара через круглое отверстие радиуса $R$ в бесконечно тонкой стенке (с параметрами газа в резервуаре $n_{0, \mathrm{Ag}}, T_{0}$ для пара серебра и $n_{0, \mathrm{He}}, T_{0}$ для гелия), и результаты расчета невязкой струи, истекающей из звукового сопла [42] (в последнем случае для варианта 11 представлены данные отдельно для струи гелия и пара серебра). Положение стенки/среза звукового сопла совпадает с плоскостью выходного отверстия рассматриваемого источника. Свободномолекулярное аналитическое решение предсказывает параметры, близкие к расчетным данным для паров серебра (варианты $1-4)$, в отличие от оценок, основанных на модели адиабатического течения невязкого газа (кривые 3 и 7 на рис. 5).

Наличие гелия в варианте 11 приводит к увеличению плотности атомов серебра в струе, ускорению пара серебра на $60 \%$ до скорости примерно $1.6 u_{0}$, превышающей скорость максимального стационарного расширения в пустоту $\left(1.4 u_{0}\right)$. При этом скорость и плотность гелия в несколько раз выше соответствующих параметров пара серебра (рис. 5, $a$ и $b$ ). На осевые распределения скорости и плотности гелия оказывает влияние наличие тепловых экранов, которое приводит к немонотонному характеру кривых в области $2<X / R<16$. Температуры гелия и серебра оказываются примерно одинаковыми в источнике и дальнем поле струи (рис. 5,c). Расчетные значения температуры как для серебра в варианте 4, так и серебра и гелия в варианте 11 практически совпадают с аналитическими данными для свободномолекулярного решения в дальнем поле струи, тогда как модель невязкого газа дает существенно более низкие температуры в струе.

Влияние расхода гелия на расход пара серебра через выходное отверстие тигля иллюстрируется данными табл. 1 и рис. 6. В таблице приведены данные для расхода пара серебра через единицу площади среза сопла $F_{e, \mathrm{Ag}}$ и центральной части подложки $F_{L, \mathrm{Ag}}$. Последний параметр является важной характеристикой процесса осаждения металлической пленки, позволяющей при этом провести сопоставление расчета с экспериментом (см. ниже).

Рассмотрим влияние определяющих параметров на расход пара серебра и гелия через выходное отверстие соплового блока. Сначала рассмотрим варианты расчета 1-4 (подача гелия в источник отсутствует), когда истечение паров серебра происходит в режиме, близком к свободномолекулярному. В этом случае массовый расход пара серебра на выходе из соплового блока можно представить как $G_{e, f}=W_{k} W_{c} G_{i}$ (здесь $G_{i}-$ расход на входе в сопловой блок (радиуса входного сечения $5 \mathrm{~mm}), W_{k}$ и $W_{c}-$ коэффициенты Клаузинга 


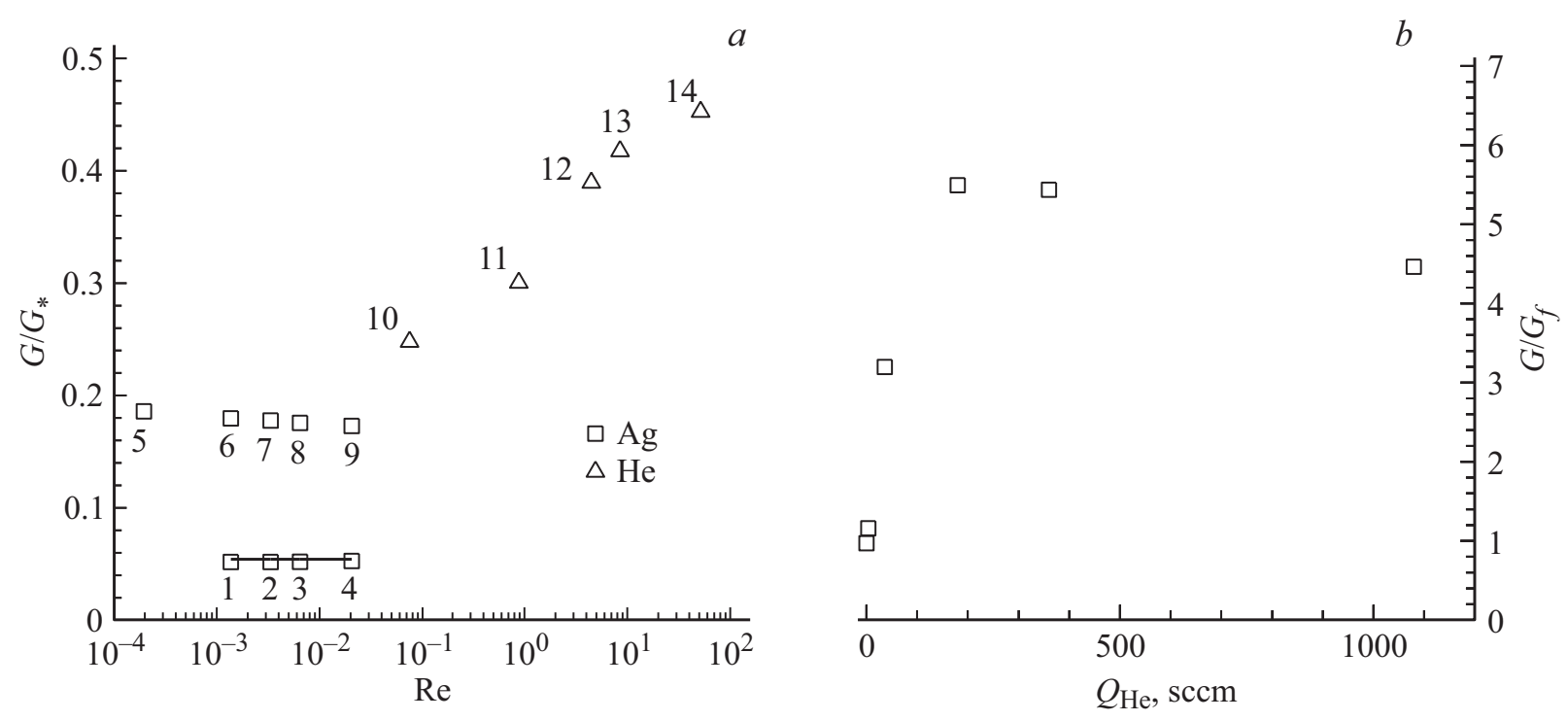

Рис. 6. $a$ - зависимость приведенных массовых расходов $\mathrm{Ag}$ и Не от числа Re, числа над точками - номер варианта расчета по табл. 1 (1-9 соответствует Ag, 10-14 - Не), сплошная линия - оценка для свободномолекулярного течения, $b-$ зависимость расхода $\mathrm{Ag}$ от расхода Не для $T_{0}=1377 \mathrm{~K}$.
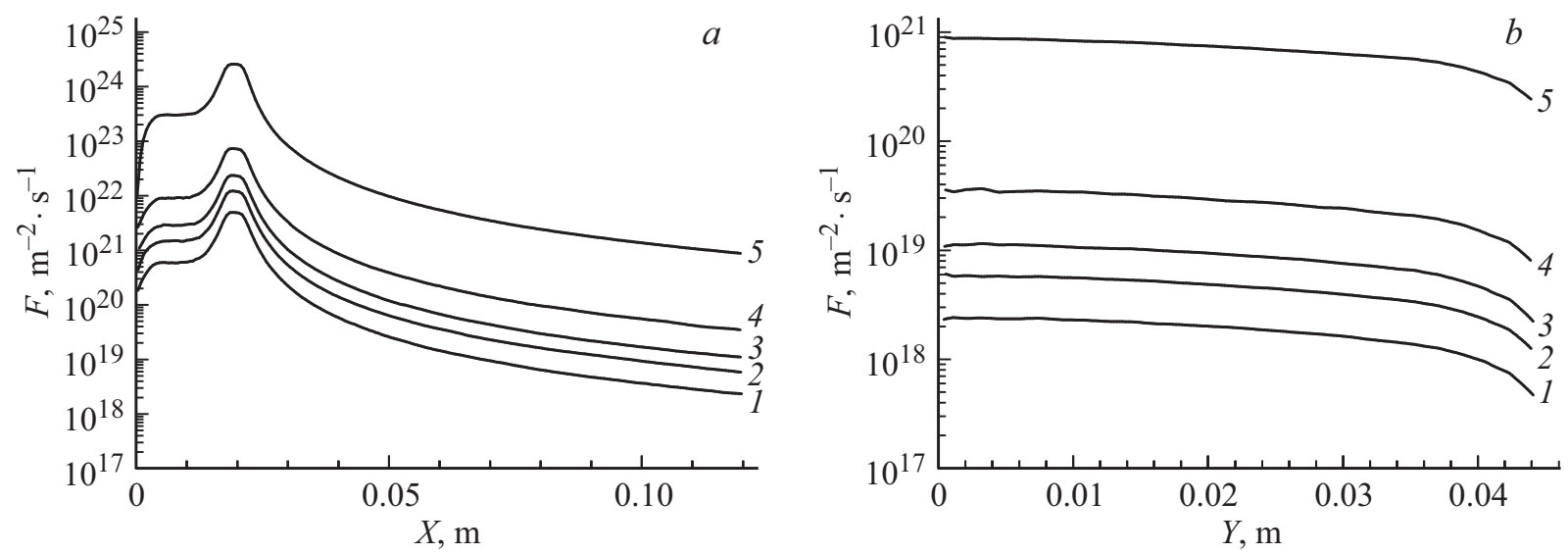

Рис. 7. Распределения потока вдоль оси $(a)$ и поперечные распределения на расстоянии $100 \mathrm{~mm}$ от источника $(b) .1-\mathrm{Ag}$, $T_{0}=1235 \mathrm{~K}$, вариант $6 ; 2-\mathrm{Ag}, T_{0}=1276 \mathrm{~K}$, вариант 7; $3-\mathrm{Ag}, T_{0}=1314 \mathrm{~K}$, вариант $8 ; 4-\mathrm{Ag}, T_{0}=1377 \mathrm{~K}$, вариант $11 ; 5-$ Не, $T_{0}=1235$ К, вариант 6.

для конфузорной и цилиндрической частей соплового блока, соответственно (см. рис. 1,c). Согласно данным [41], $W_{k} \approx 0.089, W_{c} \approx 0.52$. На рис. 6, $a$ показаны расчетные значения приведенного расхода $G_{e, \mathrm{Ag}} / G_{*}$ $\left(G_{e, \mathrm{Ag}}=m_{\mathrm{Ag}} F_{e, \mathrm{Ag}} \pi R^{2}-\right.$ массовый расход серебра через выходное отверстие соплового блока, $G_{*}-$ расход через выходное отверстие для случая изоэнтропического течения), которые практически совпадают с аналитической оценкой $G_{e, f} / G_{*}$. Из расчетов следует, что при отсутствии несущего газа примерно 97.7\% испаренных атомов серебра реконденсируются обратно на поверхности расплава (поверхность 1 радиуса $7 \mathrm{~mm}$, рис. $1, c$ ) и только $2.3 \%$ покидают источник. Это свидетельствует об установлении термодинамического равновесия между расплавом и паром при давлении насыщения $p_{0, \mathrm{Ag}}$ и работе источника как ячейки Кнудсена.
Подача гелия в источник приводит к увеличению расхода пара серебра через выходное отверстие соплового блока (рис. 6, a). Для $Q_{\mathrm{He}}=36 \mathrm{sccm}$ и исследованного диапазона температур (табл. 1) расход серебра увеличивался более чем в 3 раза. Приведенный расход гелия $G_{e, \mathrm{He}} / G_{*, \mathrm{He}}$ также показан на рис. $6, a$. Наличие соплового блока с конечной проводимостью и разреженный режим течения приводят к отличию расхода от соответствующей изоэнтропной оценки, которое уменьшается с уменьшением числа Кнудсена (ростом числа Рейнольдса). Следует отметить также, что на течение гелия влияет наличие пара серебра.

Зависимость потока серебра в выходном сечении сопла от расхода несущего газа при фиксированной температуре $T_{0}=1377 \mathrm{~K}$ показана на рис. $6, b$. С ростом расхода гелия расход пара серебра сначала резко воз- 
растает, затем достигает максимального значения при $Q_{\mathrm{He}} \approx 200 \mathrm{sccm}$ и выходит на насыщение, а при дальнейшем увеличении расхода гелия даже уменьшается. Поскольку поток металла из сопла определяет скорость осаждения пленок, т.е. характеризует эффективность источника, можно утверждать, что расход гелия в диапазоне 100-200 sccm для температуры порядка $1400 \mathrm{~K}$ является оптимальным. Причиной снижения эффективности при высоких $Q_{\text {Не }}$ является специфический характер течения паров серебра в источнике, где поток несущего газа направлен к расплаву. Расчеты показывают, что достаточно большой расход гелия приводит к поджатию пара серебра к испаряемой поверхности и препятствует движению атомов металла к сопловому блоку источника.

На рис. 7 представлены типичные осевые и поперечные (на фиксированном расстоянии от источника) распределения потоков гелия и паров серебра для режимов с несущим газом (варианты 6-8,11, табл. 1). Распределения вдоль оси имеют ярко выраженный максимум в районе выходного отверстия источника, появление которого связано с резким ростом скорости пара у среза соплового блока (рис. 5,b). Поперечные распределения потока серебра являются гладкими и относительно пологими, что является достоинством метода ВГСО, поскольку позволяет получать однородные пленки на достаточно больших поверхностях. Исключение составляют периферийные области $Y>30 \mathrm{~mm}$, где сказывается наличие тепловых экранов. Потоки через поверхность на расстоянии $L=100 \mathrm{~mm}$ от источника для всех рассматриваемых вариантов превышают значение $10^{18} \mathrm{~m}^{-2} \mathrm{~s}^{-1}$.

Наличие подложки на расстоянии $100 \mathrm{~mm}$ от среза соплового блока (примерно 65 радиусов выходного отверстия) с условиями диффузного отражения атомов гелия от нее (вариант 9) не оказывало влияния на поток атомов серебра для рассматриваемых разреженных режимов течения струи.

\section{3. Роль фонового газа в камере осаждения}

Расчетные значения потока атомов серебра на подложку заметно превышают величины потоков, оцененных на основе экспериментальных данных по осаждению пленок. В последнем случае с использованием данных СЭМ (рис. 2 и 3) оценивалась осажденная на подложку масса серебра с учетом гистограмм распределения наночастиц и в предположениях (1) полного прилипания атомов серебра к подложке, (2) сферичности наночастиц на подложке и (3) плотности наночастиц как у массивного серебра $\left(10.5 \mathrm{~g} / \mathrm{cm}^{3}\right)$. Сопоставление экспериментальных и расчетных значений потока серебра на поверхность подложки, расположенной на расстоянии $100 \mathrm{~mm}$, представлено на рис. 8, $a$. Как видно, различие составляет почти два порядка величины.

Наблюдаемое расхождение обусловлено, по всей видимости, наличием фонового газа (главным образом гелия) в вакуумной камере в процессе осаждения, не учитываемого при проведении моделирования. Так, при расходе гелия в источнике $36 \mathrm{sccm}$ давление фонового газа в камере осаждения возрастало до $19 \mathrm{~Pa}$ (значение зависит от производительности используемой откачной вакуумной системы) при температуре газа в режимах осаждения $\sim 400 \mathrm{~K}$. При относительно низких давлениях фонового газа разлет сверхзвуковой струи в затопленное пространство происходит в режиме рассеяния [43], когда частицы струи (в нашем случае атомы серебра) в результате столкновений с частицами газа выбывают из приосевой части струи, уменьшая тем самым поток на подложку. Покажем, что учет рассеяния на фоновом гелии позволяет объяснить различие в теоретическом и измеренном потоках серебра на подложку.

Выбывание частиц из оси струи можно оценить как ослабление пучка на газовой мишени [44,45]. Тогда плотность атомов серебра в струе $n_{\mathrm{Ag}}$ на расстоянии $L$ от источника равна

$$
n_{\mathrm{Ag}}(L)=n_{\mathrm{Ag}}^{0}(L) \exp \left(-\alpha_{s} L\right),
$$

где $n_{\mathrm{Ag}}^{0}-$ плотность частиц на том же расстоянии $L$ от источника без рассеяния на фоновом газе (глубокий вакуум), $\alpha_{s}=m_{\mathrm{He}} / m_{\mathrm{Ag}} \lambda_{s}-$ коэффициент ослабления, $\lambda_{s}=4 / \sqrt{2} n_{b, \mathrm{He}} \pi\left(d_{\mathrm{He}}+d_{\mathrm{Ag}}\right)^{2}-$ средняя длина свободного пробега атомов серебра в фоновом гелии, $n_{b, \mathrm{He}}-$ плотность атомов фонового газа. Фактор $m_{\mathrm{He}} / m_{\mathrm{Ag}}$ в коэффициенте $\alpha_{s}$ учитывает низкую эффективность рассеяния тяжелых атомов серебра на легких атомах гелия (эффект персистенции скоростей [46]). Тогда для давления и температуры фонового газа $p_{b, \mathrm{He}}=19 \mathrm{~Pa}$, $T_{b, \mathrm{He}}=400 \mathrm{~K}$ и $L=100 \mathrm{~mm}$ получаем $\alpha_{s}=0.45 \mathrm{~cm}^{-1}$ и $n_{\mathrm{Ag}} / n_{\mathrm{Ag}}^{0}=0.011$, что на удивление хорошо согласуется с отношением экспериментального и теоретического потоков серебра (рис. 8,a), учитывая приближенный характер сделанной оценки.

Для проверки рассмотренной модели рассеяния атомов серебра фоновым газом были осаждены пленки серебра на различных расстояниях $L$ от источника (70, 90 и $100 \mathrm{~mm})$ при фиксированных остальных параметpax (температура источника $1276 \mathrm{~K}$, время осаждения $30 \mathrm{~min}$, расход гелия $36 \mathrm{sccm}$, давление фонового газа $19 \mathrm{~Pa})$. Толщины пленок составили $8.5,1.8$ и $1 \mathrm{~nm}$ соответственно, что подтверждает существенную роль рассеяния на фоновом гелии, поскольку найденное в эксперименте уменьшение потока атомов Ag с расстоянием описывается более сильной зависимостью, чем $n_{\mathrm{Ag}} \propto L^{-2}$, характерной для случая разлета струи в глубоком вакууме [42]. Отметим, что на таких расстояниях от источника скорость уже не зависит от $L$ (рис. $5, b)$, и уменьшение потока с расстоянием определяется только падением плотности частиц. С учетом осевого распределения плотности свободной струи в вакууме и эффекта рассеяния на фоновом газе по модели (9) зависимость потока атомов серебра на подложку можно записать 

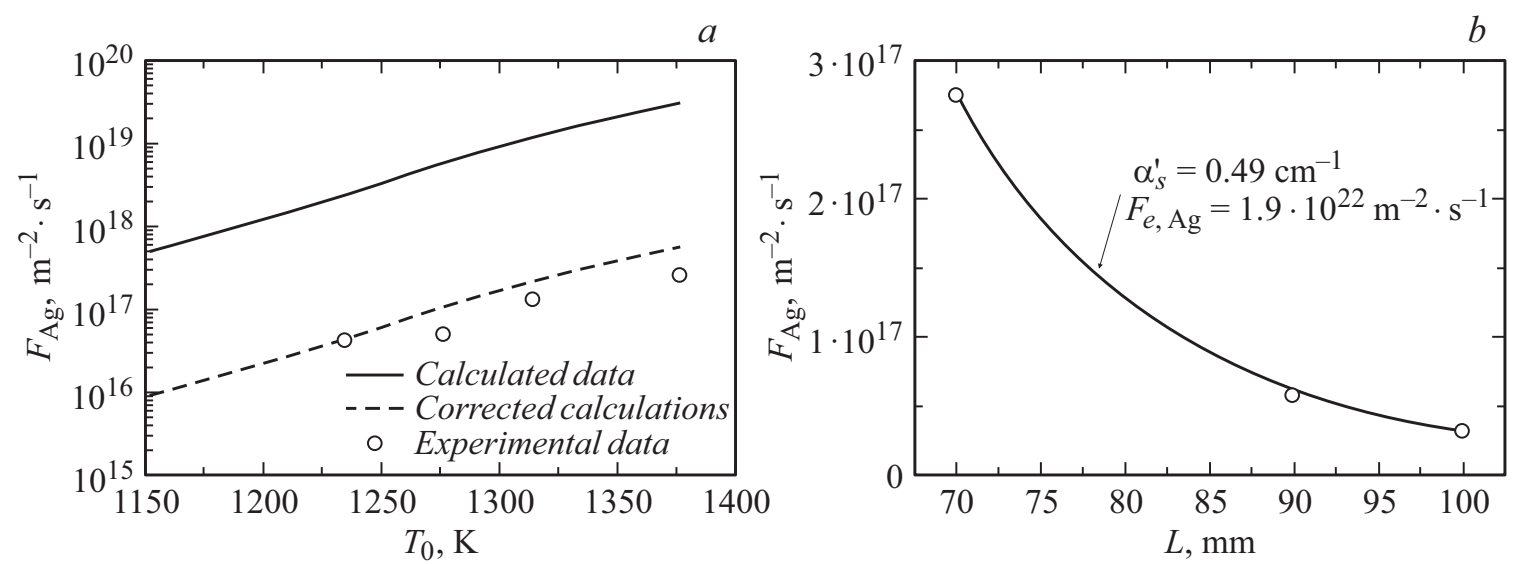

Рис. 8. $a$ - расчетная и экспериментальная зависимости потока атомов серебра на подложку от температуры источника $(L=100 \mathrm{~mm})$, штриховая кривая - расчет с поправкой на рассеяние атомов $\mathrm{Ag}$ на фоновом газе по уравнению (9); $b-$ экспериментальная зависимость потока атомов $\mathrm{Ag}$ на подложку от расстояния до источника $(T=1276 \mathrm{~K})$, кривая аппроксимация по уравнению (10).

в виде

$$
F_{\mathrm{Ag}}(L)=F_{e, \mathrm{Ag}} R^{2} \exp \left(-\alpha_{s}^{\prime} L\right) / L^{2}
$$

где $F_{e, \mathrm{Ag}}$ - поток частиц, вылетающих из сопла источника, $\alpha_{s}^{\prime}$ - эффективный коэффициент ослабления потока из-за столкновений с гелием, который следует найти из сравнения с экспериментом. Данные по зависимости толщины пленки от расстояния были аппроксимированы зависимостью (10) с использованием величин $F_{e, \mathrm{Ag}}$ и $\alpha_{s}^{\prime}$ как свободных параметров. Как видно (рис. 8, $b$ ), зависимость (10) прекрасно описывает экспериментальные данные, а найденный из условия наилучшей аппроксимации коэффициент $\alpha_{s}^{\prime}=0.49 \mathrm{~cm}^{-1}$ хорошо согласуется с полученной независимо теоретической оценкой для коэффициента ослабления в (9). Восстановленная из аппроксимации величина потока серебра на выходе из источника $F_{e, \mathrm{Ag}}=1.85 \cdot 10^{22} \mathrm{~m}^{-2} \mathrm{~s}^{-1}$ также разумно согласуется с расчетом (табл. 1, вариант 7). Отметим, что количественного совпадения для потока ожидать не следует, поскольку соотношение (10) не учитывает изменение скорости атомов серебра на начальном участке струи. Таким образом, фоновый газ при давлении 1-20 Pa, типичном для режимов ВГСО, приводит к значительному уменьшению скорости осаждения пленок, которое может быть оценено на основе модели рассеяния.

\section{4. О возможности формирования кластеров серебра в струе при ВГСО}

В работе [47] для оценки образования кластеров в струе паров металлов предложен критерий $\Gamma^{*}=\Gamma / \Gamma_{c h}$, где $\Gamma=n_{0} d^{0.85} T_{0}^{-1.29}, d=2 R, n_{0}$ - плотность пара в источнике, а величина $\Gamma_{c h}$ определяется свойствами пара. Согласно классификации, предложенной в [48], при значениях параметра $\Gamma^{*}<200$ кластеры в струе не образуются, в диапазоне $200<\Gamma^{*}<1000$ наблюдается переход от течения без конденсации к течению с кластерами, а при $\Gamma^{*}>1000$ имеет место эффективный процесс образования кластеров, размер которых достигает 100 мономеров и выше.

Для обсуждаемых выше режимов течения без несущего газа (табл. 1 , варианты $1-4)$ параметр $\Gamma^{*} \ll 200$, что говорит об отсутствии кластеров в течении. С целью определения границы „старта“ процесса формирования кластеров в струе, а также исследования влияния несущего газа на процесс образования кластеров, были проведены дополнительные расчеты течения пара серебра в смеси с несущим гелием и без него для параметров, указанных в табл. 2. Расчеты проведены в упрощенной постановке без анализа течения в источнике (см. разд. 2).

В табл. 2 представлены данные об интегральной объемной доле кластеров в струе

$$
\alpha_{c l}=\sum_{g=2}^{g_{\max }} N_{g} / \sum_{g=1}^{g_{\max }} N_{g}
$$

в области, ограниченной координатами $X_{e}<X<\left(X_{e}+15 R\right), \quad 0<Y<7 R \quad\left(N_{g}-\right.$ число частиц размера $g$ в области, $X_{e}-$ координата среза выходного отверстия источника). Для используемого в эксперименте диапазона температур $(1235<T<1377 \mathrm{~K})$ кластеры в струе не формируются. Незначительная доля кластеров (димеров) появляется при температуре источника 1773 К. В этом случае числа Кнудсена, рассчитанные по осредненным параметрам на срезе выходного отверстия соплового блока, для серебра и гелия имеют порядок 0.1 (табл. 2). Числа столкновений в таком разреженном течении не хватает для эффективного формирования кластеров. Для значений температуры источника $2123 \mathrm{~K}$ числа Кнудсена имеют порядок 0.01 и объемная доля кластеров в области расширения составляет $6 \cdot 10^{-4}$ для случая истечения без гелия и $8 \cdot 10^{-4}$ при наличии 

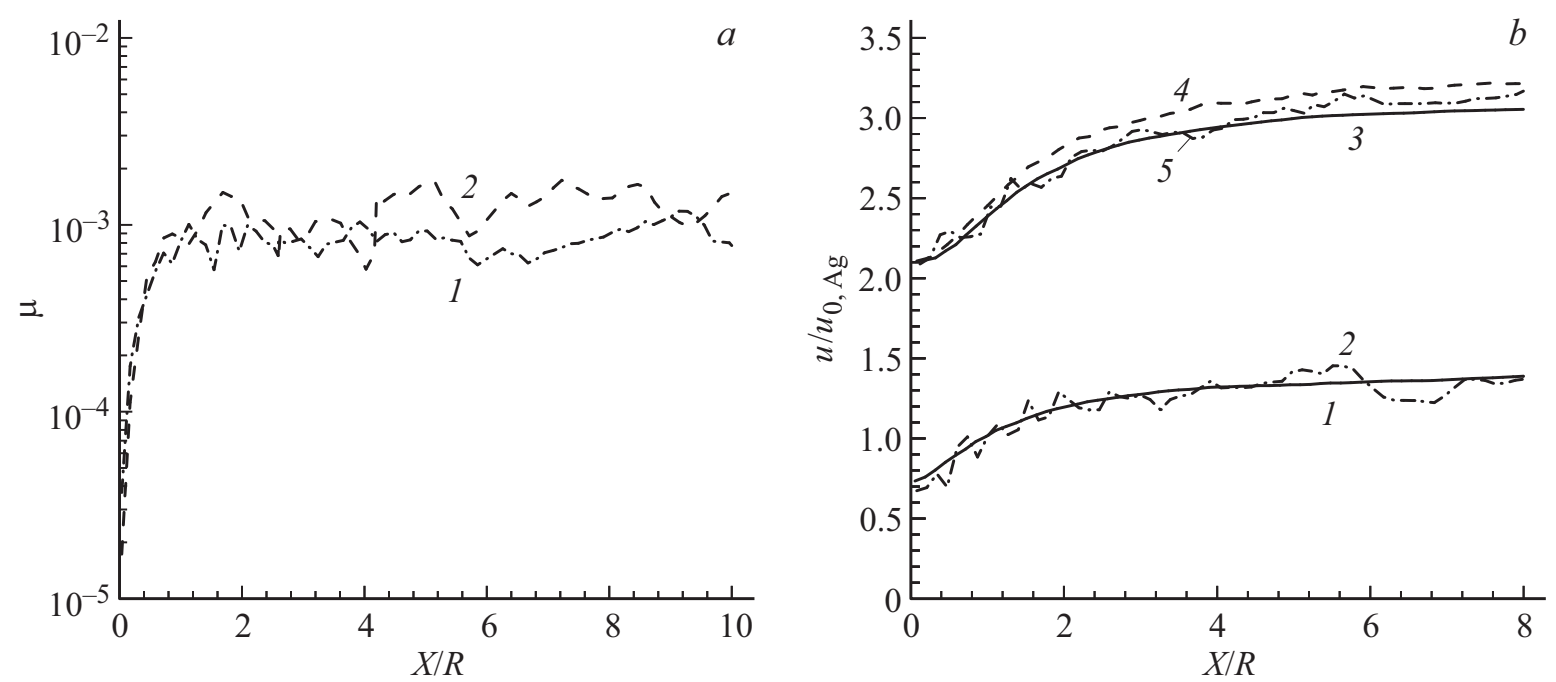

Рис. 9. $a-$ мольная концентрация димеров $\mathrm{Ag}_{2}$ в струе серебра (кривая 1, вариант расчета 19) и смеси $\mathrm{Ag}-\mathrm{He}$ (кривая 2, вариант 20); $b$ - скорости частиц в струе $\mathrm{Ag}$ (вариант 19, 1 - атомы, 2 - димеры) и смеси $\mathrm{Ag}-\mathrm{He}($ вариант 20, 3 - $\mathrm{Ag}, 4-\mathrm{He}$, $\left.5-\mathrm{Ag}_{2}\right)$.

гелия. Следует отметить, что, с одной стороны, наличие буферного газа должно способствовать интенсификации процесса кластерообразования как за счет протекания реакции (6), так и за счет дополнительного охлаждения пара. С другой стороны, наличие гелия приводит к разгону пара, его скорость в выходном отверстии возрастает, а плотность уменьшается по отношению к течению без инертного газа (в случае примерно равных значениях расхода пара серебра). Число Кнудсена для атомов серебра, рассчитанное по осредненной плотности в выходном отверстии, в случае истечения смеси пар-гелий оказывается большим по отношению к течению без гелия (табл. 2). Поэтому для варианта 20 $\left(T_{0}=2123 \mathrm{~K}\right.$ при наличии гелия) объемная интегральная доля кластеров оказывается лишь незначительно выше аналогичного параметра, полученного для той же температуры без гелия (вариант 19).

Наличие кластеров в поле течения определяется также параметрами модели конденсации в первую очередь константой скорости процесса димеризации. Ее малые значения, используемые при расчете варианта 21 (модель LDV), обусловливают меньшие значения интегральной объемной доли кластеров по сравнению с вариантами 19 и 20 (табл. 2).

Осевые распределения мольной доли димеров серебра и скорости димеров для вариантов расчета 19 и 20 приведены на рис. 9. Основными компонентами пара являются мономеры и димеры. Максимальным наблюдаемым в расчетах кластером является четырехмер $\mathrm{Ag}_{4}$. Замороженная мольная доля димеров составляет около $10^{-3}$ (рис. $9, a$ ). Основное влияние гелия в варианте 20 сводится к дополнительному разгону пара (рис. 9, $b$ ). Скорость димеров (и соответственно расход при примерно равной плотности) в варианте 20 оказывается существенно выше. Скорости мономеров и димеров серебра для каждого из вариантов примерно совпадают.

Следует обратить внимание, что эффект „замораживания“ мольной доли димеров наблюдается уже с расстояния $2 \mathrm{R}$ от среза соплового блока. Аналогичное поведение мольных долей кластеров при истечении пара из источника через отверстие в бесконечно тонкой стенке получено в работе [22]. Для рассматриваемых значений чисел Кнудсена наличие разреженного фонового газа в камере не влияет на процесс формирования кластеров, протекающий в области расширения смеси вблизи сопла, в которой эффект от столкновений с окружающей средой незначителен [49].

\section{5. Рост пленки серебра на подложке}

На основании совокупности полученных экспериментальных и расчетных данных можно заключить, что в исследуемом экспериментальном диапазоне параметров синтеза формирование наноструктурной пленки на поверхности подложки для температур источника до $1377 \mathrm{~K}$ (табл. 1) происходит в результате осаждения в основном атомов серебра, а кластеры металла в струе практически отсутствуют. Рост пленки в этом случае происходит, очевидно, по механизму ФольмераВебера [39], когда атомы диффундируют по поверхности, и в результате их столкновений происходит формирование зародышей наночастиц. Число таких зародышей определяется как вероятностью столкновений адатомов друг с другом, так и уже имеющимися на поверхности зародышами. В пользу такого механизма свидетельствует немонотонная зависимость поверхностной концентрации частиц (рис. 3). Когда стадия зародышеобразования заканчивается, наступает этап увеличения среднего размера частиц, приводящего к их коагуляции, 
а затем к формированию островков нерегулярной формы и переходу к перколяционной структуре пленки. Дальнейшее увеличение осаждаемой массы характеризуется формированием сплошного металлического покрытия (рис. 2,c).

\section{Заключение}

Проведено экспериментальное исследование и выполнено численное моделирование процесса газоструйного осаждения пленок серебра из термовакуумного источника с несущим газом гелием. Анализ результатов расчетов истечения смеси гелий-пар серебра в вакуум, выполненных методом прямого статистического моделирования, для диапазона температур источника до $1377 \mathrm{~K}$ позволяет сделать следующие выводы.

1. В случае отсутствия подачи гелия в источник истечение пара серебра происходит в свободномолекулярном режиме. Расход пара через сопловой блок может быть оценен с помощью коэффициентов Клаузинга, а для прогнозирования параметров потока могут быть использованы модели, основанные на аналитических свободномолекулярных решениях.

2. Подача гелия в источник с расходом в диапазоне 10-1000 sccm приводит к истечению смеси сереброгелий в переходном по числу Кнудсена режиме. Модели свободномолекулярного разлета и континуального невязкого течения дают при этом погрешность в оценке газодинамических параметров потока. Для прогнозирования технологических параметров требуется проведение расчетов методом прямого статистического моделирования (или иным методом решения уравнения Больцмана).

3. Мольная доля серебра в струе несущего газа значительно превышает его исходную мольную долю в источнике.

4. Скорости гелия и пара серебра в дальнем поле струи различаются более чем в 3 раза при примерно одинаковой температуре.

5. Подача несущего газа в источник приводит к существенному увеличению расхода пара серебра через выходное отверстие. Так, при расходе гелия $36 \mathrm{sccm}$ и температуре тигля $1377 \mathrm{~K}$ расход пара серебра увеличивается в 3 раза по отношению к варианту, в котором подача гелия отсутствует. При увеличении расхода несущего газа выше некоторого оптимального значения расход пара металла выходит на насыщение, а затем уменьшается.

6. Для используемых условий синтеза пленок кластеры металла в струе не образуются.

7. Наличие фонового газа в камере осаждения при давлении порядка нескольких паскалей приводит к существенному уменьшению потока атомов серебра на подложку. Для оценки этого эффекта может быть использована модель рассеяния молекулярного пучка на газовой мишени.
8. Формирование наноструктурной пленки серебра, наблюдаемое в эксперименте для рассматриваемых условий осаждения, происходит в результате образования нанокластеров (зародышей) непосредственно на поверхности подложки.

Дополнительные расчеты течения в диапазоне температур источника более $1377 \mathrm{~K}$ показали:

1. При отсутствии несущего газа кластеры в расширяющейся струе образуются, начиная с температур источника около $1750 \mathrm{~K}$.

2. Основными кластерами в струе для температур источника $1750-2150 \mathrm{~K}$ являются димеры.

3. Подача в источник несущего газа гелия приводит к росту степени кластеризации струи, а также к ускорению атомов и кластеров серебра, скорости которых оказываются примерно одинаковыми.

4. Формирование кластеров в струе происходит на расстоянии нескольких радиусов от среза сопла.

\section{Финансирование работы}

Экспериментальная часть работы выполнена при финансовой поддержке Российского научного фонда (проект № 16-19-10506). Расчетные исследования выполнены при поддержке Министерства образования и науки России (проект № 16.8548.2017/8.9) с использованием вычислительных ресурсов суперкомпьютерного центра Санкт-Петербургского политехнического университета Петра Великого.

\section{Список литературы}

[1] Hofmann S., Ducati C., Neill R.J., Piscanec S., Ferrari A.C., Geng J., Dunin-Borkowski R.E., Robertson J. // J. Appl. Phys. 2003. Vol. 94. P. 6005-6012.

[2] Haruta M. // Chem. Rec. 2003. Vol. 3. P. 75-87.

[3] Agarwal N.R., Neri F., Trusso S., Lucotti A., Ossi P.M. // Appl. Surf. Sci. 2012. Vol. 258. P. 9148-9152.

[4] Cho S.H. // Phys. Med. Biol. 2005. Vol. 50. P. 163-173.

[5] Warrender J.M., Aziz M.J. // Phys. Rev. B. 2007. Vol. 75. P. 085433.

[6] Ossi P.M., Neri F., Santo N., Trusso S. // Appl. Phys. A. 2011. Vol. 104. P. 829-837.

[7] Старинский С.В., Шухов Ю.Г., Булгаков А.В. // Письма в ЖТФ. 2016. Т. 42. Вып. 8. С. 45-52. [Starinskiy S.V., Shukhov Yu.G., Bulgakov A.V. // Tech. Phys. Lett. 2016. Vol. 42. N 4. P. 411-414.]

[8] Švorčík V., Kvítek O., Lyutakov O., Siegel J., Kolská Z. // Appl. Phys. A. 2011. Vol. 102. P. 747-751.

[9] Сафонов А.И., Старинский С.В., Сулява В.С., Тимошенко Н.И., Гатапова Е.Я. // Письма в ЖТФ. 2017. Т. 43. Вып. 3. C. 44-49. [Safonov A.I., Starinskii S.V., Sulyaeva V.S., Timoshenko N.I., Gatapova E.Y. // Tech. Phys. Lett. 2017. Vol. 43. N 2. P. 159-161.]

[10] Safonov A.I., Sulyaeva V.S., Timoshenko N.I., Kubrak K.V., Starinskiy S.V. // Phys. Lett. A. 2016. Vol. 380. P. 3919-3923.

[11] Yamada I., Takagi T. // IEEE Trans. Electron Devices. 1987. Vol. ED-34. N 5. P. 1018-1025. 
[12] Gatz P., Hagena O.F. // Appl. Surf. Sci. 1995. Vol. 91. P. 169174.

[13] Wagner K., Piseri P., Tafreshi H.V., Milani P. // J. Phys. D: Appl. Phys. 2006. N 22. P. R439-R459.

[14] Андреев М.Н., Ребров А.К., Сафонов А.И., Тимошенко Н.И. // Российские нанотехнологии. 2011. Т. 6. № 910. C. 7-10. [Andreev M.N., Rebrov A.K., Safonov A.I., Timoshenko N.I. // Nanotechnologies in Russia. 2011. Vol. 6. N 9-10. P. 587-592.]

[15] Aziz M.J. // Appl. Phys A. 2008. Vol. 93. P. 579-587.

[16] Polop C., Rosiepen C., Bleikamp S., Drese R., Mayer J., Dimyati A., Michely T. // New J. Phys. 2007. Vol. 9. P. 1-19.

[17] Старинский С.В., Суляева В.С., Шухов Ю.Г., Черков А.Г., Тимошенко Н.И., Булгаков А.В., Сафонов А.И. // Журнал структурной химии. 2017. Т. 58. № 8. С. 1631-1637. [Starinskiy S.V., Sulyaeva V.S., Shukhov Yu.G., Cherkov A.G., Timoshenko N.I., Bulgakov A.V., Safonov A.I. // J. Struct. Chem. 2017. Vol. 58. N 8. P. 1581-1587.]

[18] Fazio E., Neri F., Ossi P.M., Santo N., Trusso S. // Appl. Surf. Sci. 2009. Vol. 255. N 24. P. 9676-9679.

[19] Bird G.A. Molecular gas dynamics and the direct simulation of gas flows. Clarenton Press: Oxford, 1994.

[20] Jansen R., Wysong I., Gimelshein S., Zeifman M., Buck U. // J. Chem. Phys. 2010. Vol. 132. P. 244105.

[21] Borner A., Li Z., Levin D.A. // AIP Conf. Proc. 2012. Vol. 1501. P. 565-572.

[22] Bykov N.Y., Gorbachev Yu.E., Zakharov V.V. // AIP Conf. Proc. 2016. Vol. 1786. P. 050001.

[23] Itina T.E., Sentis M., Marine W. // Appl. Surf. Sci. 2006. Vol. 252. P. 4433-4438.

[24] Быков Н.Ю., Лукьянов Г.А. // Теплофизика и аэромеханика. 2006. T. 13. № 4. C. 569-582. [Bykov N.Yu., Lukianov G.A. // Thermophys. Aeromech. 2006. Vol. 13. N 4. P. 523-535.]

[25] Bykov N.Y., Bulgakova N.M., Bulgakov A.V., Loukianov G.A. // Appl. Phys. A. 2004. Vol. 79. N 4-6. P. 1097-1100.

[26] Электронный ресурс. Режим доступа: https://www.powerstream.com/vapor-pressure.htm

[27] Bondi A. // Phys. Chem. Vol. 68. N 3. P. 441-451.

[28] Johnston R.L. Atomic and Molecular Clusters. NY: Taylor \& Francis, 2002.

[29] Crifo J.F. // ICARUS. 1990. Vol. 84. P. 414-446.

[30] Bykov N.Y., Gorbachev Yu.E. // Appl. Math. Comp. 2017. Vol. 296. P. 215-232.

[31] Смирнов Б.М. // УФН. 1997. Т. 167. № 11. С. 1169-1200. [Smirnov B.M. // Phys. Usp. 1997. Vol. 167. N 11. P. 11171147.]

[32] Физико-химические процессы в газовой динамике. Компьютеризированный справочник в 3-х томах. T. I: Динамика физико-химических процессов в газе и плазме / Под ред. Г.Г. Черного и С.А. Лосева. М.: Изд-во МГУ, 1995. $350 \mathrm{c}$.

[33] Gaussian 09, Revision D.01 M.J. Frisch at all. Gaussian, Inc., Wallingford CT, 2013.

[34] Baulch D.L., Duxbury J., Grant S.J., Montague D.C. // J. Phys. Chem. Ref. Data. 1981. Vol. 10. P. 1-721.

[35] Gardiner W.C. Combustion chemistry. NY:: Springer, 1984. $473 \mathrm{p}$.

[36] Zhukhovitskii D.I. // J. Chem. Phys. 1994. Vol. 101. P. 50765080.

[37] Смирнов Б.М., Яценко А.С. // УФН. 1996. Т. 166. № 3. C. 224-245. [Smirnov B.M., Yatsenko A.S. // Phys. Usp. 1996. Vol. 39. P. 211-230.]
[38] Кондратьев В.Н., Никитин Е.Е. Кинетика и механизм газофазных реакций. М.: Наука, 1974. 558 с.

[39] Venablies J.A., Spliller G.D.T., Hanbukah M. // Rep. Prog. Phys. 1984. Vol. 47. N 4. P. 399-459.

[40] Tringides M.C. Surface diffusion: Atomistic and collective processes. NY: Plenum Press, 1997. 724 p.

[41] Кошмаров Ю.А., Рыжсов Ю.А. Прикладная динамика разреженного газа. М.: Машиностроение, 1977. 184 с.

[42] Ashkenas H., Sherman F.S. In: Rarefied Gas Dynamics / Ed. J.H. de Leeuw. NY.: Academ. Press, 1965. P. 84.

[43] Rebrov A.K. In: Rarefied Gas Dynamics / Ed. O.M. Belotserkovskii. NY.: Springer, 1985. P. 849.

[44] Bulgakov A.V. // Proc. SPIE. 1995. Vol. 2403. P. 75-86.

[45] Bulgakov A.V., Predtechensky M.R., Mayorov A.P. // Appl. Surf. Sci. 1996. Vol. 96-98. P. 159-163.

[46] Чепмен C., Каулинг T. Математическая теория неоднородных газов. М: ИИЛ, 1960, $511 \mathrm{c.}$

[47] Hagena O.F. // Surf. Sci. 1981. Vol. 106. P. 101-116.

[48] Hagena O.F. // Z. Phys. D. 1991. Vol. 20. P. 425-428.

[49] Дулов В.Г., Лукьянов Г.А. Газодинамика процессов истечения. Новосибирск: Наука, 1984. 236 с. 